\title{
Correction to: Spatial and Time Variability of Drought Based on SPI and RDI with Various Time Scales
}

\author{
Abdelaaziz Merabti ${ }^{1} \cdot$ Diogo S. Martins ${ }^{2}$. \\ Mohamed Meddi $^{1} \cdot$ Luis S. Pereira $^{3}$ \\ Published online: 17 February 2018 \\ (C) Springer Science+Business Media B.V., part of Springer Nature 2018
}

\section{Correction to: Water Resour Manage \\ https://doi.org/10.1007/s11269-017-1856-6}

Due to an oversight, Figure 1 image and Figure 4 caption were incorrectly captured in the original publication. The correct Figure 1 image and Figure 4 caption are shown below.

The online version of the original article can be found at https://oi.org/10.1007/s11269-017-1856-6

\section{Luis S. Pereira}

lspereira@isa.ulisboa.pt; luis.santospereira@gmail.com

Ecole Nationale Supérieure d'Hydraulique de Blida, Laboratoire GEE, Blida, Algeria

2 Instituto Dom Luiz (IDL), Faculdade de Ciências, Universidade de Lisboa, Lisbon, Portugal

3 LEAF - Linking Landscape, Environment, Agriculture and Food, Instituto Superior de Agronomia, Universidade de Lisboa, Lisbon, Portugal 
Fig. 1 should read:

\section{a) Annual precipitation amount $(\mathrm{mm})$}
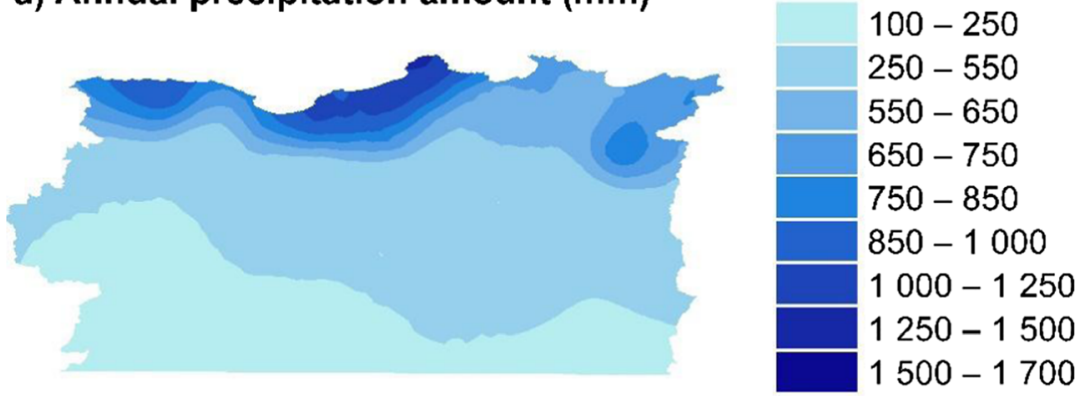

\section{b) Precipitation Concentration Index}

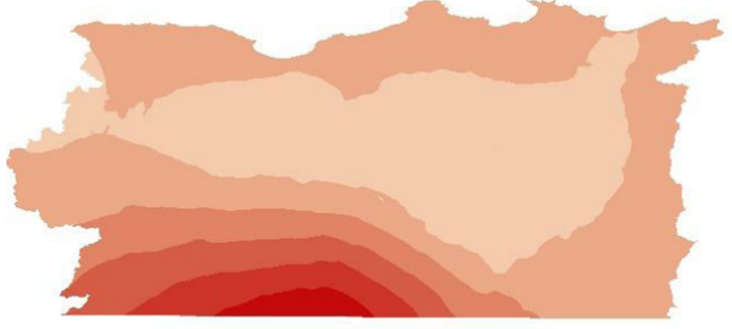

c) Aridity Index

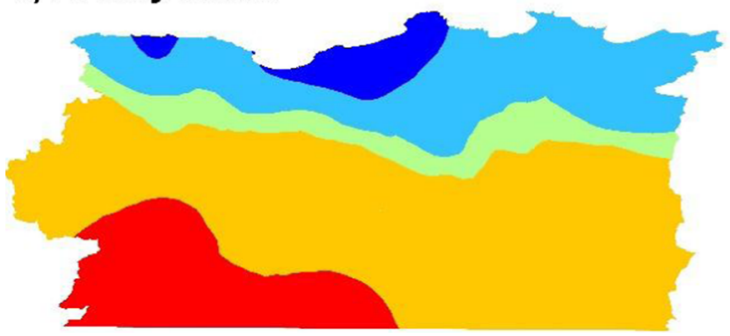

The caption of Fig. 4 should read:

Fig. 4 Number of dryness and wetness events identified for each category referring to the rotated PC scores of RDI ( $\square$ ) and SPI ( $\square$ ) computed with the time-scales of 3, 6 and 12 months, $1980-2014$ 